\title{
Association of ACE2 genetic polymorphisms with hypertension- related target organ damages in south Xinjiang
}

\author{
Yi Luo ${ }^{1} \cdot$ Cheng Liu ${ }^{1,2,3} \cdot$ Tianwang Guan ${ }^{2} \cdot$ Yanfang $\mathrm{Li}^{2} \cdot$ Yanxian Lai ${ }^{1} \cdot$ Fang Li $^{3} \cdot$ Haiyan Zhao ${ }^{3} \cdot$ Tutiguli Maimaiti $^{3}$. \\ Abudurexiti Zeyaweiding ${ }^{3}$
}

Received: 22 August 2018 / Revised: 14 October 2018 / Accepted: 14 October 2018 / Published online: 12 December 2018

(c) The Author(s) 2019. This article is published with open access

\begin{abstract}
Essential hypertension (EH) is a principal contributing factor in worldwide cardiovascular disease mortality. Although interventions that minimize environmental risk factors for EH are associated with reduced cardiovascular disease, such approaches are limited for individuals with high genetic EH risk. In this study, we investigated possible associations between ACE2 polymorphisms and hypertension-related target organ damages in south Xinjiang, China. Four hundred and two hypertensive patients were enrolled as study participants in an EH group, and 233 normotensive individuals were enrolled as control subjects. Participants were recruited from the south Xinjiang region. Fourteen ACE2 polymorphisms were genotyped by matrix-assisted laser desorption ionization time-of-flight mass spectrometry. Risk genotypes of rs2074192 (TT $+\mathrm{CT}$, OR $=1.72,95 \%$ CI: $1.17-2.53$ ), rs 2106809 (TT, OR $=1.71,95 \%$ CI: $1.13-2.58)$, rs4240157 (CC+CT, OR $=1.99,95 \%$ CI: 1.17-3.41), rs4646155 (TT+CT, OR $=1.94,95 \%$ CI: $1.06-3.54)$, rs $4646188(\mathrm{TT}+\mathrm{CT}, \mathrm{OR}=3.25,95 \%$ CI: $1.95-5.41)$, rs4830542 (CC+CT, OR $=1.88,95 \%$ CI: $1.10-3.23)$, and rs879922 (CC+CG, OR $=4.86,95 \%$ CI: 2.74-8.64) were associated with EH. Hypertensive patients carrying the control genotype of rs2074192 (CC, OR $=2.37,95 \%$ CI: 1.28-4.39) were associated with CAS $\geq 50 \%$, while those carrying a high-EH-risk genotype of rs4240157 (OR $=2.62,95 \% \mathrm{CI}$ : 1.24-5.54), rs4646155 (OR $=2.44,95 \%$ CI: $1.16-5.10)$, or rs4830542 (CC+CT, OR $=2.20,95 \%$ CI: $1.03-4.69)$ were associated with atrial fibrillation (AF), larger left atrial diameter, and higher levels of renin-angiotensin-aldosterone system (RAAS) activation (renin and angiotensin I/II). In conclusion, the ACE2 variant rs2074192 was associated with EH and EH with CAS $250 \%$, while 3 ACE2 variants (rs4240157, rs4646155, and rs4830542) were associated with EH- and hypertension-related AF and left atrial remodeling in south Xinjiang, China.
\end{abstract}

Keywords Association $\cdot$ ACE2 polymorphism $\cdot$ Essential hypertension $\cdot$ Target organ damage $\cdot$ South Xinjiang

These authors contributed equally: Yi Luo, Cheng Liu

Electronic supplementary material The online version of this article (https://doi.org/10.1038/s41440-018-0166-6) contains supplementary material, which is available to authorized users.

Cheng Liu

eyliucheng@scut.edu.cn

1 Department of Cardiology, Guangzhou First People's Hospital, Medical School, South China University of Technology, 510180 Guangzhou, China

2 Department of Cardiology, Guangzhou First People's Hospital, Guangzhou Medical University, 510180 Guangzhou, China

3 Department of Cardiology, Shufu People's Hospital, Xinjiang Uygur Autonomous Region (XUAR), 844100 Kashgar Region, China

\section{Introduction}

Essential hypertension (EH) is attributable to both genetic and environmental factors and is a major contributor to worldwide cardiovascular disease (CVD) mortality [1]. A recent prospective cohort study indicates that the prevalence of hypertension in China overall is as high as $32.5 \%$ [2], and the EH control rate for Chinese patients overall is only $4.2 \%$, significantly lower than the $30-55 \%$ rate reported for Western patients [3, 4]. Under these circumstances, addressing the challenge of preventing and treating $\mathrm{EH}$ in China should focus on decreasing prevalent risk factors that potentially affect all members of society $[5,6]$. Increasingly, comprehensive management of multiple modifiable risk factors (e.g., unhealthy diet, lack of physical activity, smoking, obesity, dyslipidemia, abnormal glucose metabolism, and obstructive 
Table1 Baseline characteristics of study participants

\begin{tabular}{|c|c|c|c|}
\hline & Normotensive & Hypertensive & $P$ value \\
\hline$N$ & 233 & 402 & - \\
\hline Han:Uygur & $116: 117$ & $222: 180$ & 0.186 \\
\hline Male:Female & $93: 140$ & $166: 236$ & 0.733 \\
\hline Age (Years) & $57.7 \pm 12.6$ & $58.8 \pm 10.9$ & 0.298 \\
\hline Smoking $(\%)$ & $43(18.3)$ & $82(20.4)$ & 0.553 \\
\hline Drinking (\%) & $40(17.2)$ & 83 (20.6) & 0.285 \\
\hline $\mathrm{SBP}(\mathrm{mm} \mathrm{Hg})$ & $116.2 \pm 9.5$ & $155.8 \pm 13.3$ & $<0.001$ \\
\hline DBP (mm Hg) & $73.9 \pm 7.4$ & $85.5 \pm 13.5$ & $<0.001$ \\
\hline BMI $\left(\mathrm{Kg} / \mathrm{m}^{2}\right)$ & $23.5 \pm 4.6$ & $26.1 \pm 4.1$ & $<0.001$ \\
\hline TRIG (mmol/L) & $1.29 \pm 0.95$ & $1.35 \pm 0.63$ & 0.350 \\
\hline $\mathrm{CHOL}(\mathrm{mmol} / \mathrm{L})$ & $4.56 \pm 1.12$ & $4.64 \pm 1.21$ & 0.370 \\
\hline HDL-C (mmol/L) & $1.24 \pm 0.41$ & $1.20 \pm 0.28$ & 0.088 \\
\hline LDL-C (mmol/L) & $2.38 \pm 0.76$ & $2.86 \pm 0.80$ & $<0.001$ \\
\hline $\mathrm{Lp}(\mathrm{a})(\mathrm{g} / \mathrm{L})$ & $0.24 \pm 0.19$ & $0.24 \pm 0.21$ & 0.621 \\
\hline ApoA1/ApoB & $1.32 \pm 0.42$ & $1.38 \pm 0.55$ & 0.105 \\
\hline FBG $(\mathrm{mmol} / \mathrm{L})$ & $5.90 \pm 1.89$ & $6.02 \pm 1.92$ & 0.422 \\
\hline $\mathrm{Cr}(\mu \mathrm{mol} / \mathrm{L})$ & $74.5 \pm 24.0$ & $77.7 \pm 23.2$ & 0.103 \\
\hline BUN (mmol/L) & $5.20 \pm 1.99$ & $5.28 \pm 1.72$ & 0.614 \\
\hline $\mathrm{UA}(\mu \mathrm{mol} / \mathrm{L})$ & $308.5 \pm 135.7$ & $355.4 \pm 131.7$ & $<0.001$ \\
\hline ALT (U/L) & $25.3 \pm 15.0$ & $26.8 \pm 22.1$ & 0.347 \\
\hline AST (U/L) & $23.3 \pm 12.2$ & $23.3 \pm 13.7$ & 0.965 \\
\hline Alb (g/L) & $37.2 \pm 4.4$ & $37.6 \pm 6.0$ & 0.412 \\
\hline $\mathrm{Na}^{+}(\mathrm{mmol} / \mathrm{L})$ & $138.1 \pm 3.4$ & $140.3 \pm 4.3$ & $<0.001$ \\
\hline $\mathrm{Ca}^{2+}(\mathrm{mmol} / \mathrm{L})$ & $2.19 \pm 0.11$ & $2.20 \pm 0.12$ & 0.096 \\
\hline $\mathrm{K}^{+}(\mathrm{mmol} / \mathrm{L})$ & $4.03 \pm 0.41$ & $3.97 \pm 0.49$ & 0.097 \\
\hline $\mathrm{Mg}^{2+}(\mathrm{mmol} / \mathrm{L})$ & $1.01 \pm 0.18$ & $1.00 \pm 0.18$ & 0.511 \\
\hline HsCRP (mg/L) & $10.8 \pm 18.9$ & $14.9 \pm 24.1$ & 0.018 \\
\hline ACE (U/L) & $36.6 \pm 19.8$ & $42.0 \pm 25.7$ & 0.006 \\
\hline Renin (pg/mL) & $24.5 \pm 28.1$ & $34.7 \pm 33.3$ & $<0.001$ \\
\hline Ang I (ng/L) & $2.07 \pm 1.44$ & $2.70 \pm 1.77$ & $<0.001$ \\
\hline Ang II (ng/L) & $62.7 \pm 93.9$ & $90.6 \pm 123.9$ & 0.001 \\
\hline ALD (ng/L) & $187.2 \pm 114.4$ & $247.0 \pm 133.0$ & $<0.001$ \\
\hline
\end{tabular}

sleep apnea) has been associated with lower blood pressure and lower incidence of EH-related cardiovascular events, including arteriosclerosis cardiovascular disease (ASCVD), atrial fibrillation (AF), heart failure, and other events $[3,7]$.

By contrast, nonbehavioral/environmental/lifestyle-associated EH risk factors, including male gender, increasing age, and, particularly, genetic factors, will require different interventional approaches. Genetic background notwithstanding, the cardiovascular benefits from management of those reversible cardiovascular risk factors could be weakened or offset by high genetic risk because it is impossible to modify the genetic structure $[8,9]$. The time of intervention (which is much more important than intervention itself sometimes, as described above) is the deciding factor affecting the final outcome, so clinical assessment of genetic background is a feasible way to find the optimal intervention time for the population at different levels of EH genetic risk.

Studies to identify associated disease risk gene variants in the Chinese population are essential to begin developing individualized precision approaches to prevent EH. Numerous candidate genes have been implicated in susceptibility to EH. In recent years, genes of the renin-angiotensin-aldosterone system (RAAS) have received a good deal of attention. Angiotensin-converting enzyme 2 (ACE2) is a key RAAS enzyme and a new target for prevention and treatment of EH [10]. ACE2 maps to chromosome Xp22, spans $39.98 \mathrm{~kb}$ of genomic DNA, and contains 20 introns and 18 exons. The ACE2 gene encodes a type I membrane-bounded glycoprotein composed by 805 amino acids. Functional domains include a C-terminal transmembrane anchoring region, $\mathrm{N}$-terminal signal peptide region, and an HEXXH zinc-binding metalloprotease motif. The ACE2 gene exhibits a high degree of genetic polymorphism. Unlike the association of ACE2 singlenucleotide polymorphisms (SNPs) with EH in Europeans (rs2074192, rs233575, and rs2158083) [11], Australians (rs1978124 and rs2285666) [12], Indians (rs2285666) [13] and Koreans (rs1514282 and rs1514283) [14], ACE2 polymorphisms associated with EH in the Chinese population display considerable diversity between inhabitants of southern vs. northern China, Han vs. non-Han nationality, and between females and males. A meta-analysis of ACE2 gene polymorphism and $\mathrm{EH}$ association confirmed rs2285666 and rs2106809 were correlated with hypertension risk in persons of Han descent [15]. In Han people of northern China, males carrying the $\mathrm{G}$ allele and females of genotype GG of rs2285666 had increased risk of EH, and the male $\mathrm{G}$ allele frequency of rs 1978124 was similar to that of rs2285666 [16]. In the northwestern region, rs2285666 was not associated with EH in Han Chinese but was related to hypertension risk among Dongxiang people [17]. In central China, no significant relationship was found between rs2285666 or rs2106809 and EH in persons of Han descent [18]. In southern China, Han females with CC+CT genotypes for rs2106809 had higher EH risk [19]. SNPs rs4646155 and rs879922 were not associated with EH among the Han [20]. SNP rs2285666 was linked to EH in Li people [21].

Not all ACE2 variants are associated with risk of EH, and among risk-associated ACE2 polymorphic loci, higher $\mathrm{EH}$ risk is also linked to geographical, ethnic, and genderrelated factors. In this study, we investigated possible associations between ACE2 gene variation and hypertension-related target organ damage in south Xinjiang, China. 


\section{Materials and methods}

\section{Study participants}

This study was reviewed and approved by the Ethics Committee of Guangzhou First People's Hospital, South China University of Technology. A total of 402 consecutive patients with $\mathrm{EH}$ and 233 normotensive subjects from the south Xinjiang region were enrolled in the study from 2012 to 2017. All participants were long residents of the region and were from multigeneration resident families. All participants shared the same high-salt, high-fat diet. The newly hypertensive patients were diagnosed according to the criteria of the 1999 World Health Organization/International Society of Hypertension (WHO/ISH) as follows: [1] systolic blood pressure (SBP) $\geq 140 \mathrm{~mm} \mathrm{Hg}$ and/or diastolic blood pressure (DBP) $\geq 90 \mathrm{~mm} \mathrm{Hg}$; [2] diagnosed with $\mathrm{EH}$ for the first time and did not receive any antihypertensive treatment; and [3] family history of high blood pressure. Exclusion criteria: [1] secondary hypertension, due to conditions such as renal parenchymal hypertension, renal vascular hypertension (renal artery stenosis), endocrine diseases such as primary aldosteronism, pheochromocytoma, Cushing syndrome, and hyperthyroidism; [2] white coat hypertension; and [3] any other diseases or drugs that may affect blood pressure. The healthy normotensive subjects were defined as those without a history of hypertension and with blood pressure measurements of $\mathrm{SBP}<130 \mathrm{~mm}$ $\mathrm{Hg}$ and $\mathrm{DBP}<85 \mathrm{~mm} \mathrm{Hg}$ [22]. Blood pressure was measured in the seated position after $10 \mathrm{~min}$ of rest using a mercury sphygmomanometer by experienced and certified examiners, and it was measured in the brachial artery 3 times at 5-min intervals in at least two separate visits to the health-care office. The mean of the last two measurements per visit was recorded as representative of clinical BP. Bilateral carotid duplex scanning was performed on admission to the study. A comparison of the baseline characteristics is shown in Table 1 .

\section{Carotid and cardiac ultrasonography}

Bilateral carotid and cardiac ultrasonic scanning was performed on admission to the study. The near and far walls of the bilateral common carotid artery, bifurcations, and $1 \mathrm{~cm}$ of the internal and external carotid arteries were scanned for the presence of carotid arteriosclerosis stenosis (CAS) $\geq 50 \%$ (recorded as the average of two independent experienced physician measurements according to the measurement of the degree of stenosis used in the North American Symptomatic Carotid Endarterectomy Trial [23]) with a $3 / 9 \mathrm{MHz}$ ultrawideband linear array transducer (iU22, Philips, NL). Left atrial diameter (LAD) was measured using M-mode or two-dimensional echocardiography in the parasternal long- axis view at the end-ventricular systole with a $1.7 / 3.4 \mathrm{MHz}$ linear array transducer (Vivid 7, GE Healthcare, USA) over 4 cardiac cycles according to recommendations for chamber quantification from the American Society of Echocardiography [24].

\section{Genotyping assay}

Genomic DNA was extracted from whole blood using the Maxwell RSC Whole Blood DNA Kit (Promega, Madison, WI), quantified using a NanoDrop-1000 (ThermoFisher, Waltham, MA) and diluted to $10 \mathrm{ng} / \mu \mathrm{L}$ concentration. Fourteen ACE2 SNPs (rs1978124, rs2048683, rs2074192, rs2106809, rs2285666, rs233575, rs4240157, rs4646142, rs4646155, rs4646156, rs4646188, rs4830542, rs6632677, and rs879922) were identified based on existing literature and human genome sequence databases. Primers for ACE2 SNPs were designed based upon sequence information from GenBank using Primer 5.0 (Whitehead Institute Cambridge, MA, USA) and Operon's Oligo software 7.60 (OperonTechnologies Inc., Alameda, California, USA). Primers are shown in Supplementary Table 1. ACE2 SNPs were analyzed using the Sequenom MassARRAY system according to previously described methods [25]. Genotyping accuracy was determined by genotype concordance between duplicate samples and was $100 \%$ for each SNP.

\section{Statistical analysis}

Because ACE2 is located on the $\mathrm{X}$ chromosome, Hardy-Weinberg equilibrium was assessed only for females, as shown in Supplementary Table 2. Analysis was performed using SPSS version 20 (SPSS, Chicago, IL) and PASS version 15 (Statistical Solutions Ltd, Cork, Ireland). Categorical variables (nationality, gender, smoking, drinking, $\mathrm{EH}$, and $\mathrm{EH}$ complicated with $\mathrm{CAS} \geq 50 \%$ or $\mathrm{AF}$ ) are presented as frequencies. The relationship between each ACE2 SNP and those categorical variables was assessed using the chi-square test. The odds ratio (OR) between the control genotype and the high-hypertensive-risk genotype for each ACE2 SNP for categorical variables was evaluated using binary logistic regression. Considering the possible false-positive risk to the final result, Bonferroni adjustment was applied to adjust the $P$ value obtained in multilogit regression. Continuous variables (age, SBP, DBP, body mass index (BMI), blood biochemical index, and LAD) are presented as the mean \pm SD. Significant differences for continuous variables were analyzed by two-way analysis of variance (ANOVA), one-way ANOVA, or the independentsample $t$ test, according to our research design. The least significant difference test was further used to assess differences between two subgroups after variance analysis, to show distinct differences with homogeneous variance, 
Table 2 Association of ACE2 SNPs with EH in participants

\begin{tabular}{llllll}
\hline ACE2 SNPs & & Normotensive $(N(\%))$ & Hypertensive $(N(\%))$ & OR $(95 \% \text { CI })^{\mathrm{a}}$ & $P$ value $^{\mathrm{a}}$ \\
\hline rs2074192 & CC & $118(50.6)$ & $162(40.3)$ & 1.00 & \\
& TT+CT & $115(59.4)$ & $240(59.7)$ & $1.72(1.17-2.53)$ & 0.006 \\
rs2106809 & CC+CT & $121(51.9)$ & $175(43.5)$ & 1.00 & \\
& TT & $112(48.1)$ & $227(56.5)$ & $1.71(1.13-2.58)$ & 0.012 \\
rs4240157 & CC+CT & $43(18.5)$ & $92(22.9)$ & $1.99(1.17-3.41)$ & 0.012 \\
& TT & $190(81.5)$ & $310(77.1)$ & 1.00 & \\
rs4646155 & CC & $211(90.6)$ & $334(83.1)$ & 1.00 & \\
& TT+CT & $22(9.4)$ & $68(16.9)$ & $1.94(1.06-3.54)$ & 0.030 \\
rs4646188 & CC & $74(31.8)$ & $85(21.1)$ & 1.00 & \\
& TT+CT & $159(68.2)$ & $317(78.9)$ & $3.25(1.95-5.41)$ & $<0.001$ \\
rs4830542 & CC+CT & $43(18.5)$ & $90(22.4)$ & $1.88(1.10-3.23)$ & 0.020 \\
& TT & $190(81.5)$ & $312(77.6)$ & 1.00 & \\
rs879922 & CC+CG & $40(17.2)$ & $131(32.6)$ & $4.86(2.74-8.64)$ & $<0.001$ \\
& GG & $193(82.8)$ & $271(67.4)$ & 1.00 & \\
\hline
\end{tabular}

${ }^{a}$ After adjustment for nationality, gender, age, smoking, BMI, TRIG, LDL-C, HDL-C, Lp(a), FBS, UA, HsCRP, and Ang II while the Games-Howell test was used for heterogeneous variance. A $P$ value $<0.05$ was considered statistically significant. All probabilities are two-tailed.

\section{Result}

\section{Characteristics of the study participants}

As shown in Table 1, hypertensive and normotensive subjects showed significant differences in SBP, DBP, BMI, low-density lipoprotein cholesterol (LDL-C), serum uric acid, serum sodium, high-sensitivity C-reactive protein, and the activation of RAAS $(P<0.001$ or $P=$ 0.001 ) but not in nationality, age, gender, smoking, drinking, hypertriglyceridemia, hypercholesterolemia, high-density lipoprotein cholesterol (HDL-C), lipoprotein A), fasting blood glucose, renal function (creatinine, blood urea nitrogen), liver function (alanine transaminase, aspartate aminotransferase, albumin), or blood electrolytes (calcium, potassium, and magnesium) (all $P$ $>0.05)$

\section{Association of ACE2 SNPs with EH}

As shown in Table 2, ACE2 SNPs rs2074192 $(P=$ $0.006)$, rs2106809 $(P=0.012)$, rs4240157 $(P=0.012)$, rs4646155 $(P=0.030), \quad$ rs4646188 $\quad(P<0.001)$, rs4830542 $(P=0.020)$, and rs879922 $(P<0.001)$ were significantly associated with EH except rs1978124, rs2048683, rs2285666, rs233575, rs4646142, rs4646156, and rs6632677 (all $P>0.05$, see Supplementary Table 3 ).

\section{Association of ACE2 SNPs with EH complicated by CAS $\geq \mathbf{5 0 \%}$}

As shown in Table 3, ACE2 SNPs rs2074192 $(P=0.006)$, rs2285666 $(P=0.024)$, and rs4646142 $(P=0.023)$ were associated with $\mathrm{EH}$ complicated by CAS $\geq 50 \%$.

\section{Association of ACE2 SNPs with EH-related left atrial enlargement (LAE)}

As shown in Table 4, no significant difference was observed between hypertensive and normotensive participants in LAD size (all $P>0.05$ ), while significant difference were observed between the high-EH-risk and control genotypes of the EH-risk-related ACE2 SNPs rs4240157 $(P=0.007)$, rs4646155 $(P=0.029)$, and rs4830542 $(P=0.003)$.

\section{Association of ACE2 SNPs with EH complicated by AF}

As shown in Table 5, ACE2 SNPs rs2285666 $(P=0.039)$, rs4240157 $(P=0.011)$, s4646142 $(\mathrm{P}=0.014), \mathrm{rs} 4646155$ $(P=0.018)$, and $\operatorname{rs} 4830542(P=0.042)$ were associated with EH complicated by AF.

\section{Association of ACE2 SNPs with RAAS activation}

As shown in Table 6, significant differences were observed between hypertensive and normotensive participants in the levels of ACE, renin, angiotensin I/II (ANG I/ II), and aldosterone (ALD) (all $P<0.05$ ). Significant differences were also observed between the high-EH-risk and control genotypes of the EH-risk-related ACE2 SNPs in the levels of ACE (rs2106809 $(P=0.008)$, rs4646188 $(P=0.032)$, 
Table 3 Association of ACE2 SNPs with EH complicated by $\mathrm{CAS} \geq 50 \%$ in hypertensive participants

\begin{tabular}{llllll}
\hline ACE2 SNPs & & Non-CAS $\geq 50 \%(N(\%))$ & CAS $\geq 50 \%(N(\%))$ & OR $(95 \% \text { CI })^{\mathrm{a}}$ & $P$ value $^{\mathrm{a}}$ \\
\hline rs2074192 & CC & $126(37.2)$ & $36(57.1)$ & $2.37(1.28-4.39)$ & 0.006 \\
& TT+CT & $213(62.8)$ & $27(42.9)$ & 1.00 & \\
rs2285666 & CC & $131(38.6)$ & $15(23.8)$ & 1.00 & \\
& TT+CT & $208(61.4)$ & $48(76.2)$ & $2.28(1.11-4.65)$ & 0.024 \\
rs4646142 & CC+CG & $206(60.8)$ & $48(76.2)$ & $2.28(1.12-4.66)$ & 0.023 \\
& GG & $133(39.2)$ & $15(23.8)$ & 1.00 & \\
\hline
\end{tabular}

${ }^{a}$ After adjustment for nationality, gender, age, smoking, BMI, LDL-C, HDL-C, FBS, UA, HsCRP, and Ang II
Table 4 Association of ACE2 SNPs with EH-related left atrial enlargement in participants

\begin{tabular}{|c|c|c|c|c|}
\hline \multirow[t]{2}{*}{ ACE2 SNPs } & & \multicolumn{3}{|l|}{$\mathrm{LAD}(\mathrm{cm})$} \\
\hline & & Normotensive & Hypertensive & $P$ value \\
\hline \multirow[t]{3}{*}{ rs2074192 } & $\mathrm{CC}$ & $2.77 \pm 0.26$ & $2.76 \pm 0.41$ & 0.834 \\
\hline & $\mathrm{TT}+\mathrm{CT}$ & $2.73 \pm 0.33$ & $2.81 \pm 0.46$ & 0.056 \\
\hline & $P$ value & 0.332 & 0.229 & \\
\hline \multirow[t]{3}{*}{ rs2106809 } & $\mathrm{CC}+\mathrm{CT}$ & $2.74 \pm 0.34$ & $2.83 \pm 0.37$ & 0.054 \\
\hline & TT & $2.76 \pm 0.26$ & $2.77 \pm 0.49$ & 0.881 \\
\hline & $P$ value & 0.582 & 0.186 & \\
\hline \multirow[t]{3}{*}{ rs2285666 } & $\mathrm{CC}$ & $2.74 \pm 0.33$ & $2.86 \pm 0.51$ & 0.040 \\
\hline & $\mathrm{TT}+\mathrm{CT}$ & $2.76 \pm 0.28$ & $2.76 \pm 0.40$ & 0.976 \\
\hline & $P$ value & 0.771 & 0.047 & \\
\hline \multirow[t]{3}{*}{ rs4240157 } & $\mathrm{CC}+\mathrm{CT}$ & $2.72 \pm 0.27$ & $2.93 \pm 0.40$ & $<0.001$ \\
\hline & TT & $2.76 \pm 0.31$ & $2.75 \pm 0.45$ & 0.861 \\
\hline & $P$ value & 0.404 & 0.001 & \\
\hline \multirow[t]{3}{*}{ rs4646142 } & $\mathrm{CC}+\mathrm{CG}$ & $2.77 \pm 0.27$ & $2.76 \pm 0.40$ & 0.706 \\
\hline & GG & $2.72 \pm 0.34$ & $2.86 \pm 0.51$ & 0.016 \\
\hline & $P$ value & 0.212 & 0.044 & \\
\hline \multirow[t]{3}{*}{ rs 4646155} & $\mathrm{CC}$ & $2.75 \pm 0.31$ & $2.77 \pm 0.45$ & 0.551 \\
\hline & $\mathrm{TT}+\mathrm{CT}$ & $2.75 \pm 0.24$ & $2.90 \pm 0.42$ & 0.032 \\
\hline & $P$ value & 0.989 & 0.023 & \\
\hline \multirow[t]{3}{*}{ rs4646188 } & $\mathrm{CC}$ & $2.79 \pm 0.32$ & $2.78 \pm 0.37$ & 0.802 \\
\hline & $\mathrm{TT}+\mathrm{CT}$ & $2.73 \pm 0.29$ & $2.80 \pm 0.46$ & 0.059 \\
\hline & $P$ value & 0.154 & 0.693 & \\
\hline \multirow[t]{3}{*}{ rs4830542 } & $\mathrm{CC}+\mathrm{CT}$ & $2.72 \pm 0.27$ & $2.94 \pm 0.39$ & $<0.001$ \\
\hline & TT & $2.76 \pm 0.31$ & $2.75 \pm 0.45$ & 0.779 \\
\hline & $P$ value & 0.404 & $<0.001$ & \\
\hline \multirow[t]{3}{*}{ rs879922 } & $\mathrm{CC}+\mathrm{CG}$ & $2.69 \pm 0.26$ & $2.80 \pm 0.45$ & 0.051 \\
\hline & GG & $2.76 \pm 0.31$ & $2.79 \pm 0.44$ & 0.462 \\
\hline & $P$ value & 0.143 & 0.823 & \\
\hline
\end{tabular}

rs4830542 $(P=0.48)$, and $\operatorname{rs} 879922(P=0.005))$, renin (rs4240157 $(P=0.016)$, rs4646155 $(P=0.009)$, rs4830542 $(P=0.022)$, and rs879922 $(P<0.001))$, ANG I (rs4646188 $(P=0.028)$ and rs879922 $(P=0.005))$, and ANG II $($ rs4240157 $(P=0.001), \quad$ rs4830542 $\quad(P=0.001), \quad$ and rs879922 $(P<0.001))$ but not ALD (all $P>0.05)$.

\section{Discussion}

EH is rapidly developing into an epidemic and has dramatically increased the global cardiovascular events that have become a serious public health problem. The outlook for EH treatment and prevention is more severe in China [1], especially in minority areas (e.g., the Xinjiang region [26]). The prevalence of $\mathrm{EH}$ among adults in Xinjiang is higher than the national average, and there are significant differences in prevalence between different ethnicities, including Han and Uygurs [27]. This study addressed possible relationships between ACE2 polymorphisms and EH in people of the south Xinjiang region of China. We found that certain genotypes of rs2074192 (TT+CT), rs2106809 (TT), rs4240157 (CC+CT), rs4646155 (TT+CT), and rs4830542 $(\mathrm{CC}+\mathrm{CT})$ were linked to moderate $\mathrm{EH}$ risk $(\mathrm{OR}=$ 1.71-1.99), while rs4646188 (TT+CT) and rs879922 (CC $+\mathrm{CG})$ were linked to high $\mathrm{EH}$ risk $(\mathrm{OR}=3.25-4.86)$. Our findings are consistent with the observations by Patel et al. [28], who reported ACE2 SNPs (rs2074192, rs4240157, and rs4646188) were associated with higher hypertension risk while rs1978124 was not in a diabetic Australian Caucasian population, and by Benjafield et al. [12], who reported that rs1978124 and rs2285666 were not correlated with EH in Australian persons of Anglo-Celtic descent. With regard to gender (see Supplementary Table 4), we found a high $\mathrm{EH}$ risk $(\mathrm{OR}=2.24)$ in males with the rs4646188 TT genotype compared to those with the CC genotype and a higher risk $(\mathrm{OR}=6.37)$ in female carriers of the $\mathrm{C}$ allele $(\mathrm{TT}+\mathrm{CT})$. However, other ACE2 SNP alleles, rs2074192 (TT), rs2285666 (CC), rs4646142 (GG), and rs4646155 (TT), were only associated with increased EH risk $(\mathrm{OR}=1.95-3.47)$ in males, while rs2106809 (TT), rs4240157 (CC+CT), rs4830542 $(\mathrm{CC}+\mathrm{CT})$, and rs879922 $(\mathrm{CC}+\mathrm{CG})$ were associated with increased $\mathrm{EH}$ risk only in females $\quad(\mathrm{OR}=2.56-4.76)$. SNP rs2285666 (CC) was associated with higher EH risk in northern China (not in northwestern or central China) but only associated with male hypertensive patients in Xinjiang in our study. Our results are in partial agreement with the study by Malard et al. [11], who reported that rs2074192 was correlated with 
Table 5 Association of ACE2 SNPs with EH complicated by $\mathrm{AF}$ in hypertensive participants

\begin{tabular}{llllll}
\hline ACE2 SNPs & & Non-AF $(N(\%))$ & AF $(N(\%))$ & OR $(95 \% \text { CI })^{\mathrm{a}}$ & $P$ value $^{\mathrm{a}}$ \\
\hline rs2285666 & CC & $109(33.4)$ & $37(48.7)$ & $1.95(1.03-3.66)$ & 0.039 \\
& TT + CT & $217(66.6)$ & $39(51.3)$ & 1.00 & \\
rs4240157 & CC + CT & $65(19.9)$ & $27(35.5)$ & $2.62(1.24-5.54)$ & 0.011 \\
& TT & $261(80.1)$ & $49(64.5)$ & 1.00 & \\
rs4646142 & CC + CG & $215(66.0)$ & $39(51.3)$ & 1.00 & 0.014 \\
& GG & $111(34.0)$ & $37(48.7)$ & $2.36(1.19-4.66)$ & \\
rs4646155 & CC & $276(84.7)$ & $58(76.3)$ & 1.00 & 0.018 \\
& TT+CT & $50(15.3)$ & $18(23.7)$ & $2.44(1.16-5.10)$ & 0.042 \\
rs4830542 & CC + CT & $65(19.9)$ & $25(32.9)$ & $2.20(1.03-4.69)$ & \\
& TT & $261(80.1)$ & $51(67.1)$ & 1.00 & \\
\hline
\end{tabular}

${ }^{a}$ After adjustment for nationality, gender, age, smoking, BMI, SBP, DBP, LDL-C, HDL-C, FBS, UA, HsCRP, Ang II, and LAD
$\mathrm{EH}$ in males while rs233575 was correlated in both males and females with European male ancestry. However, SNP rs233575 was related to hypertension in neither males nor females in our study.

The Framingham Study showed that starting from 115/ $75 \mathrm{~mm} \mathrm{Hg}$, the risk for cardiovascular events (e.g., ASCVD) increases following the increase in blood pressure [29]. In this study, we found that two ACE2 SNPs (rs2074192 and rs879922) were associated with moderate and high risk of $\mathrm{EH}$, and both of these loci have also been associated with sudden cardiac arrest [30] but not with the recurrence risk of stroke [31]. Although three SNPs (rs1978124, rs2285666, and rs4646142) were not associated with EH (see Supplementary Table 3), they have exhibited associations with ASCVD (e.g., coronary heart disease [32, 33], ischemic stroke [34]) as well as cardiovascular death [35, 36], suggesting that there is a common genetic basis for hypertension and ASCVD [37]. According to the 2014 NLA recommendations [38], CAS $\geq 50 \%$ is defined as a new type of ASCVD. This is based on findings that, in patients with $\mathrm{CAS} \geq 50 \%$, the 10 -year risk of cardiovascular events is concordant with that of patients suffering from CVD. In our study, we further found that hypertensive patients with the genotype rs2074192 (CC), rs2285666 (TT+CT), or rs4646142 were linked to high risk of CAS $\geq 50 \%$ (see Table 3 and Supplementary Table 5). After hypertension, dyslipidemia is the second leading cause of ASCVD [1]. We observed that the lipid spectrum seemed to be in the "normal" range in both the hypertensive and normotensive participants. LDL-C level in the hypertensive group was higher compared with the normotensive group, being even $>1.8 \mathrm{mmol} / \mathrm{L}$ (the highest target achievement of LDL-C in extremely high-risk EH patients) and was close to level of hypertensive patients in the United States [39]. Compared with EH patients without CAS $\geq$ $50 \%$, those with CAS $\geq 50 \%$ exhibited higher LDL-C and lower HDL-C and were not associated with the three arteriosclerosis risk-related ACE2 SNPs (see Supplementary Table 6).

On the other hand, LAE is often detected in hypertensive patients even before left ventricular hypertrophy (LVH) becomes noticeable, due to increased diastolic or systolic overloading of the left atrium. Indeed, four ACE2 variants that we found to be related to $\mathrm{EH}$ risk (rs2074192, rs4240157, rs4646188, and rs879922) have also been correlated with $\mathrm{LVH}[28,40]$. LAE, unlike $\mathrm{LVH}$, is not used as an indicator of EH-related risk or prognosis in clinical hypertension guidelines, but it is nevertheless an early marker of hypertension-related left ventricular remodeling. We found that not all LVH risk-related ACE2 variation was associated with LAE. SNP rs4240157 was further associated with LAE risk in this study. Beyond that, we newly found that LAD was obviously enlarged in hypertensive patients with the high-EH-risk genotype rs4830542 (CC $+\mathrm{CT})$ or rs4646155 (TT+CT). LAE persists during EHrelated heart remodeling, finally leading to AF. In the Framingham Heart Study [41], every 5-mm increase in LAD increased the development of AF by $39 \%$. A recent study correlated rs6632677 with left ventricular remodeling [42], and it has been associated with AF risk in the Chinese population [43]. In contrast, we found that rs6632677 was not associated with risk of AF (see Supplementary Table 7), and the genotypes of the 3 ACE2 SNPs associated with LAE were also associated with increased AF risk $(\mathrm{OR}=$ 2.20-2.62).

The activation of RAAS runs through the whole cardiovascular event chain (i.e., atherosclerosis, left atrial remodeling, $\mathrm{AF}$, etc.), and $\mathrm{EH}$ is an initiating risk factor for the process [44]. The circulating and tissue RAAS of EH complicated with cardiovascular risk (i.e., dyslipidemia) are excessively activated [45], but genetic ACE2 mutation promotes the development of atherosclerosis and left heart remodeling [46, 47]. SNP rs2074192 has been associated with circulating RAAS activation in hypertensive patients 
Table 6 Association of ACE2 SNPs with the RAAS activity in participants

\begin{tabular}{|c|c|c|c|c|c|c|c|c|c|c|c|}
\hline \multirow{2}{*}{\multicolumn{2}{|c|}{ ACE2 SNPs }} & \multicolumn{3}{|l|}{$\mathrm{ACE}(\mathrm{U} / \mathrm{L})$} & \multicolumn{3}{|l|}{$\operatorname{Renin}(\mathrm{pg} / \mathrm{mL})$} & \multicolumn{4}{|c|}{ Ang I (ng/L) } \\
\hline & & Normotensive & Hypertensive & $P$ value & Normotensive & e Hypertensive & e $P$ value & \multicolumn{2}{|c|}{ Normotensive } & Hypertensive & $P$ value \\
\hline \multirow[t]{3}{*}{ rs2074192 } & $\mathrm{CC}$ & $35.3 \pm 18.6$ & $41.9 \pm 31.6$ & 0.044 & $25.8 \pm 28.8$ & $34.9 \pm 35.4$ & 0.022 & \multicolumn{2}{|c|}{$2.00 \pm 1.41$} & $2.78 \pm 1.83$ & $<0.001$ \\
\hline & $\mathrm{TT}+\mathrm{CT}$ & $35.9 \pm 19.9$ & $42.1 \pm 20.9$ & 0.009 & $23.3 \pm 27.3$ & $34.5 \pm 31.9$ & 0.001 & \multicolumn{2}{|c|}{$2.14 \pm 1.47$} & $2.64 \pm 1.73$ & 0.008 \\
\hline & $P$ value & 0.791 & 0.931 & & 0.487 & 0.894 & & \multicolumn{2}{|c|}{0.445} & 0.452 & \\
\hline \multirow[t]{3}{*}{ rs2106809 } & $\mathrm{CC}+\mathrm{CT}$ & $34.2 \pm 20.4$ & $38.5 \pm 22.3$ & 0.094 & $24.9 \pm 31.0$ & $30.4 \pm 33.3$ & 0.151 & \multicolumn{2}{|c|}{$2.23 \pm 1.59$} & $2.45 \pm 1.69$ & 0.261 \\
\hline & TT & $37.1 \pm 17.9$ & $44.7 \pm 27.7$ & 0.009 & $24.1 \pm 24.7$ & $37.9 \pm 33.1$ & $<0.001$ & \multicolumn{2}{|c|}{$1.89 \pm 1.25$} & $2.89 \pm 1.81$ & $<0.001$ \\
\hline & $P$ value & 0.257 & 0.016 & & 0.825 & 0.026 & & \multicolumn{2}{|c|}{0.065} & 0.015 & \\
\hline rs4240157 & $\mathrm{CC}+\mathrm{CT}$ & $38.9 \pm 13.8$ & $45.1 \pm 16.6$ & 0.024 & $26.2 \pm 24.3$ & $42.4 \pm 34.2$ & 0.002 & $1.90=$ & & $3.08 \pm 1.76$ & $<0.001$ \\
\hline & TT & $34.9 \pm 20.2$ & $41.1 \pm 27.8$ & 0.008 & $24.2 \pm 28.9$ & $32.4 \pm 32.8$ & 0.005 & $2.10=$ & & $2.58 \pm 1.76$ & 0.001 \\
\hline & $P$ value & 0.121 & 0.187 & & 0.676 & 0.011 & & 0.412 & & 0.018 & \\
\hline rs4646155 & $\mathrm{CC}$ & $35.3 \pm 18.1$ & $41.7 \pm 25.5$ & 0.002 & $25.2 \pm 28.2$ & $36.4 \pm 34.6$ & $<0.001$ & $2.05=$ & & $2.66 \pm 1.75$ & $<0.001$ \\
\hline & $\mathrm{TT}+\mathrm{CT}$ & $38.1 \pm 28.1$ & $43.3 \pm 26.9$ & 0.443 & $18.4 \pm 26.1$ & $26.1 \pm 24.4$ & 0.208 & $2.14=$ & & $2.88 \pm 1.85$ & 0.097 \\
\hline & $P$ value & 0.654 & 0.657 & & 0.279 & 0.020 & & 0.795 & & 0.355 & \\
\hline rs4646188 & $\mathrm{CC}$ & $37.6 \pm 21.9$ & $46.7 \pm 38.7$ & 0.078 & $19.5 \pm 22.2$ & $32.6 \pm 31.4$ & 0.002 & $2.09=$ & & $2.21 \pm 1.61$ & 0.629 \\
\hline & $\mathrm{TT}+\mathrm{CT}$ & $34.7 \pm 17.8$ & $40.7 \pm 20.8$ & 0.002 & $26.9 \pm 30.2$ & $35.2 \pm 33.8$ & 0.009 & $2.06=$ & & $2.83 \pm 1.79$ & $<0.001$ \\
\hline & $P$ value & 0.310 & 0.059 & & 0.058 & 0.519 & & 0.864 & & 0.004 & \\
\hline rs4830542 & $\mathrm{CC}+\mathrm{CT}$ & $38.9 \pm 13.8$ & $45.7 \pm 16.2$ & 0.013 & $26.2 \pm 24.3$ & $42.1 \pm 34.5$ & 0.003 & $1.90=$ & & $3.03 \pm 1.75$ & $<0.001$ \\
\hline & TT & $34.9 \pm 20.2$ & $40.9 \pm 27.7$ & 0.009 & $24.2 \pm 28.9$ & $32.5 \pm 32.7$ & 0.004 & $2.10=$ & & $2.60 \pm 1.76$ & 0.001 \\
\hline & $P$ value & 0.121 & 0.119 & & 0.676 & 0.016 & & 0.412 & & 0.041 & \\
\hline rs879922 & $\mathrm{CC}+\mathrm{CG}$ & $39.3 \pm 14.2$ & $46.4 \pm 16.8$ & 0.010 & $26.3 \pm 25.2$ & $47.1 \pm 36.7$ & $<0.001$ & $1.96=$ & & $3.12 \pm 1.83$ & $<0.001$ \\
\hline & GG & $34.8 \pm 20.1$ & $39.9 \pm 28.8$ & 0.036 & $24.2 \pm 28.7$ & $28.6 \pm 29.8$ & 0.106 & $2.09=$ & & $2.49 \pm 1.70$ & 0.006 \\
\hline & $P$ value & 0.099 & 0.018 & & 0.657 & $<0.001$ & & 0.559 & & 0.001 & \\
\hline ACE2 SNP & & & II (ng/L) & & & & ALD (ng/L & & & & \\
\hline & & & motensive & Hypert & ensive & $P$ value & Normotens & & Нype & rtensive & $P$ value \\
\hline rs2074192 & $\mathrm{CC}$ & & $5 \pm 95.3$ & $95.5 \pm$ & 103.1 & 0.281 & $202.0 \pm 130$ & & $248 . ?$ & \pm 126.9 & 0.003 \\
\hline & $\mathrm{TT}+$ & $-\mathrm{CT}$ & $2 \pm 63.6$ & $97.0 \pm$ & 119.0 & 0.047 & $192.8 \pm 93$ & & 239. & \pm 118.5 & $<0.001$ \\
\hline & $P$ va & alue & & 0.896 & & & 0.537 & & 0.46 & & \\
\hline rs2106809 & $\mathrm{CC}-$ & $+\mathrm{CT}$ & $2 \pm 99.2$ & $79.8 \pm$ & 109.9 & 0.667 & $190.4 \pm 91$ & & 235. & \pm 122.0 & $<0.001$ \\
\hline & $\mathrm{TT}$ & & $1 \pm 77.8$ & $109.2 \pm$ & 113.5 & $<0.001$ & $205.1 \pm 13$ & & 248. & \pm 121.8 & 0.003 \\
\hline & $P$ va & lue & & 0.009 & & & 0.322 & & $0.31 \mathrm{C}$ & & \\
\hline rs4240157 & $\mathrm{CC}-$ & $+\mathrm{CT}$ & $7 \pm 73.4$ & $133.5 \pm$ & 124.2 & 0.003 & $199.3 \pm 17$ & & 258.2 & \pm 117.8 & 0.023 \\
\hline & $\mathrm{TT}$ & 78. & $3 \pm 93.0$ & $85.4 \pm$ & 106.9 & 0.430 & $197.0 \pm 95$ & & 238.2 & \pm 122.9 & $<0.001$ \\
\hline & $P$ va & lue & & 0.001 & & & 0.933 & & 0.16 & & \\
\hline rs4646155 & $\mathrm{CC}$ & & \pm 91.1 & $91.5 \pm$ & 13.2 & 0.192 & $199.1 \pm 110$ & & 245.8 & \pm 122.3 & $<0.001$ \\
\hline & $\mathrm{TT}+$ & $-\mathrm{CT}$ & $2 \pm 74.7$ & $120.6 \pm$ & 108.3 & 0.038 & $182.1 \pm 14$ & & 227. & \pm 119.6 & 0.141 \\
\hline & $P$ va & alue & & 0.048 & & & 0.505 & & 0.258 & & \\
\hline rs4646188 & $\mathrm{CC}$ & & $2 \pm 85.2$ & $77.8 \pm$ & 106.2 & 0.975 & $198.0 \pm 112$ & & 259. & \pm 136.1 & 0.002 \\
\hline & $\mathrm{TT}+$ & $-\mathrm{CT}$ & $2 \pm 91.9$ & $101.4 \pm$ & 114.1 & 0.022 & $197.2 \pm 115$ & 4.4 & 238. & \pm 117.6 & $<0.001$ \\
\hline & $P$ va & lue & & 0.087 & & & 0.959 & & 0.16 & & \\
\hline rs4830542 & $\mathrm{CC}-$ & $+\mathrm{CT}$ & $7 \pm 73.4$ & $133.6 \pm$ & 125.6 & 0.013 & $199.3 \pm 17$ & & 254 & \pm 116.5 & 0.032 \\
\hline & TT & 78. & $3 \pm 93.0$ & $85.7 \pm$ & 106.6 & 0.411 & $197.0 \pm 95$ & & 239. & \pm 123.3 & $<0.001$ \\
\hline & $P$ va & alue & & 0.001 & & & 0.904 & & 0.298 & & \\
\hline rs879922 & $\mathrm{CC}-$ & $+\mathrm{CG}$ & 575.9 & $133.7 \pm$ & 127.2 & 0.019 & $206.4 \pm 17$ & & $259 . ?$ & \pm 124.5 & 0.037 \\
\hline & GG & 77. & \pm 92.4 & $78.4 \pm$ & 100.5 & 0.956 & $195.6 \pm 95$ & & 234.8 & \pm 120.0 & $<0.001$ \\
\hline & $P$ va & alue & & $<0.001$ & & & 0.712 & & 0.05 & & \\
\hline
\end{tabular}


[48], while rs4646155 and rs879922 were not [20]. By contrast, our findings found that not all EH risk-related ACE2 variants (i.e., rs2074192) were associated with the plasma levels of RAAS, not all non-EH risk-related ACE2 variants (i.e., rs4646156) were associated with the plasma levels of RAAS (i.e., renin, see Supplementary Table 8), and the EH risk-related SNP rs879922 was significantly correlated to RAAS activation (i.e., ACE, renin, and ANG I/ II). The genotypes (i.e., rs2074192 (CC), rs2285666 (TT $+\mathrm{CT})$, and rs4646142 (CC+CG)) related to high atherosclerosis $(\mathrm{CAS} \geq 50 \%$ ) risk were not associated with high levels of RAAS (see Table 6 and Supplementary Table 8), and the genotypes (i.e., rs42040157 (CC+CT), rs4646155 $(\mathrm{TT}+\mathrm{CT})$, and rs $4830542(\mathrm{CC}+\mathrm{CT}))$ associated with LAE were associated with high levels of RAAS (see Table 6), suggesting that ACE2 genetic variants have the potential to affect circulating RAAS activation.

Some limitations should be mentioned. First, since our sample size was not large enough, further prospective large sample studies are needed to validate our findings. Second, the possibility of false-positive findings should be considered, especially for secondary studies based on our results.

In conclusion, the ACE2 variant rs2074192 was associated with EH and EH with CAS $\geq 50 \%$, while three ACE2 variants (rs4240157, rs4646155, and rs4830542) were associated with EH- and hypertension-related AF and left atrial remodeling. Specially, our data show for the first time that the ACE2 SNP rs4830542 had those effects, while rs2048683 did not, suggesting that the ACE2 SNP rs4830542 may be a novel genetic susceptibility marker for EH (especially in females) and EH-related cardiovascular events. Our observations further support that the genetic predisposition of ACE2 SNPs associated with the risk of $\mathrm{EH}$ and EH with cardiovascular risk factors and events warrants large-scale evaluation in the south Xinjiang region.

Acknowledgements This study was supported by grants from the Project of Natural Science Foundation of XUAR, China (NQ. 201318101-12), and the Science and Technology Planning Project of Guangdong Province, China (NQ. 2014A020212372). We thank all individuals for their participation in the research.

\section{Compliance with ethical standards}

Conflict of interest The authors declare that they have no conflict of interest.

Open Access This article is licensed under a Creative Commons Attribution 4.0 International License, which permits use, sharing, adaptation, distribution and reproduction in any medium or format, as long as you give appropriate credit to the original author(s) and the source, provide a link to the Creative Commons license, and indicate if changes were made. The images or other third party material in this article are included in the article's Creative Commons license, unless indicated otherwise in a credit line to the material. If material is not included in the article's Creative Commons license and your intended use is not permitted by statutory regulation or exceeds the permitted use, you will need to obtain permission directly from the copyright holder. To view a copy of this license, visit http://creativecommons. org/licenses/by/4.0/.

\section{References}

1. GBD 2016 Causes of Death Collaborators. Global, regional, and national age-sex specific mortality for 264 causes of death, 19802016: a systematic analysis for the Global Burden of Disease Study 2016. Lancet. 2017;390:1151-210.

2. Lewington S, Lacey B, Clarke R, Guo Y, Kong XL, Yang L, et al. The burden of hypertension and associated risk for cardiovascular mortality in China. JAMA Intern Med. 2016;176:524-32.

3. Kotseva K, De Bacquer D, De Backer G, Ryden L, Jennings C, Gyberg V, et al. Lifestyle and risk factor management in people at high risk of cardiovascular disease. A report from the European Society of Cardiology European Action on Secondary and Primary Prevention by Intervention to Reduce Events (EUROASPIRE) IV cross-sectional survey in 14 European regions. Eur J Prev Cardiol. 2016;23:2007-18.

4. Egan BM, Li J, Hutchison FN, Ferdinand KC. Hypertension in the United States, 1999 to 2012: progress toward Healthy People 2020 goals. Circulation. 2014;130:1692-9.

5. Kelly TN, Gu D, Chen J, Huang JF, Chen JC, Duan X, et al. Hypertension subtype and risk of cardiovascular disease in Chinese adults. Circulation. 2008;118:1558-66.

6. Bi Y, Jiang Y, He J, Xu Y, Wang L, Xu M, et al. Status of cardiovascular health in Chinese adults. J Am Coll Cardiol. 2015;65:1013-25.

7. Colpani V, Baena CP, Jaspers L, van Dijk GM, Farajzadegan Z, Dhana $\mathrm{K}$, et al. Lifestyle factors, cardiovascular disease and allcause mortality in middle-aged and elderly women: a systematic review and meta-analysis. Eur J Epidemiol. 2018;33:831-45.

8. Pazoki R, Dehghan A, Evangelou E, Warren H, Gao H, Caulfield $\mathrm{M}$, et al. Genetic predisposition to high blood pressure and lifestyle factors: associations with midlife blood pressure levels and cardiovascular events. Circulation. 2018;137:653-61.

9. Klimentidis YC, Bea JW, Lohman T, Hsieh PS, Going S, Chen Z. High genetic risk individuals benefit less from resistance exercise intervention. Int J Obes. 2015;39:1371-5.

10. Velkoska E, Patel SK, Burrell LM. Angiotensin converting enzyme 2 and diminazene: role in cardiovascular and blood pressure regulation. Curr Opin Nephrol Hypertens. 2016;25:384-95.

11. Malard L, Kakinami L, O'Loughlin J, Roy-Gagnon MH, Labbe A, Pilote $\mathrm{L}$, et al. The association between the angiotensin-converting enzyme- 2 gene and blood pressure in a cohort study of adolescents. BMC Med Genet. 2013;14:117.

12. Benjafield AV, Wang WY, Morris BJ. No association of angiotensin-converting enzyme 2 gene (ACE2) polymorphisms with essential hypertension. Am J Hypertens. 2004;17:624-8.

13. Patnaik M, Pati P, Swain SN, Mohapatra MK, Dwibedi B, Kar SK, et al. Association of angiotensin-converting enzyme and angiotensin-converting enzyme-2 gene polymorphisms with essential hypertension in the population of Odisha, India. Ann Hum Biol. 2014;41:145-52.

14. Song SB, Jin HS, Hong KW, Lim JE, Moon JY, Jeong KH, et al. Association between renin-angiotensin-aldosterone system-related genes and blood pressure in a Korean population. Blood Press. 2011;20:204-10.

15. Yang M, Zhao J, Xing L, Shi L. The association between angiotensin-converting enzyme 2 polymorphisms and essential hypertension risk: a meta-analysis involving 14,122 patients. J Renin Angiotensin Aldosterone Syst. 2015;16:1240-4. 
16. Niu W, Qi Y, Hou S, Zhou W, Qiu C. Correlation of angiotensinconverting enzyme 2 gene polymorphisms with stage 2 hypertension in Han Chinese. Transl Res. 2007;150:374-80.

17. Yi L, Gu YH, Wang XL, An LZ, Xie XD, Shao W, et al. Association of ACE, ACE2 and UTS2 polymorphisms with essential hypertension in Han and Dongxiang populations from northwestern China. J Int Med Res. 2006;34:272-83.

18. Fan XH, Wang YB, Wang H, Sun K, Zhang WL, Song XD, et al. Polymorphisms of angiotensin-converting enzyme (ACE) and ACE2 are not associated with orthostatic blood pressure dysregulation in hypertensive patients. Acta Pharmacol Sin. 2009;30:1237-44.

19. Chen YY, Liu D, Zhang P, Zhong JC, Zhang CJ, Wu SL, et al. Impact of ACE2 gene polymorphism on antihypertensive efficacy of ACE inhibitors. J Hum Hypertens. 2016;30:766-71.

20. Liu D, Chen Y, Zhang P, Zhong J, Jin L, Zhang C, et al. Association between circulating levels of ACE2-Ang-(1-7)-MAS axis and ACE2 gene polymorphisms in hypertensive patients. Medicine. 2016;95:e3876.

21. Lu N, Yang Y, Wang Y, Liu Y, Fu G, Chen D, et al. ACE2 gene polymorphism and essential hypertension: an updated metaanalysis involving 11,051 subjects. Mol Biol Rep. 2012;39:6581-9.

22. Marchesi C, Maresca AM, Solbiati F, Franzetti I, Laurita E, Nicolini E, et al. Masked hypertension in type 2 diabetes mellitus. Relationship with left-ventricular structure and function. Am J Hypertens. 2007;20:1079-84.

23. Meschia JF, Klaas JP, Brown RD Jr., Brott TG. Evaluation and management of atherosclerotic carotid stenosis. Mayo Clin Proc. 2017;92:1144-57.

24. Lang RM, Badano LP, Mor-Avi V, Afilalo J, Armstrong A, Ernande L, et al. Recommendations for cardiac chamber quantification by echocardiography in adults: an update from the American Society of Echocardiography and the European Association of Cardiovascular Imaging. Eur Heart J Cardiovasc Imaging. 2015;16:233-70.

25. Bundock PC, Eliott FG, Ablett G, Benson AD, Casu RE, Aitken $\mathrm{KS}$, et al. Targeted single nucleotide polymorphism (SNP) discovery in a highly polyploid plant species using 454 sequencing. Plant Biotechnol J. 2009;7:347-54.

26. Wang Y, Zhang J, Ding Y, Zhang M, Liu J, Ma J, et al. Prevalence of hypertension among adults in remote rural areas of Xinjiang, China. Int J Environ Res Public Health. 2016;13:524.

27. Dai CF, Xie X, Ma YT, Yang YN, Li XM, Fu ZY, et al. Relationship between CYP17A1 genetic polymorphism and essential hypertension in a Chinese population. Aging Dis. 2015;6:486-98

28. Patel SK, Wai B, Ord M, MacIsaac RJ, Grant S, Velkoska E, et al. Association of ACE2 genetic variants with blood pressure, left ventricular mass, and cardiac function in Caucasians with type 2 diabetes. Am J Hypertens. 2012;25:216-22.

29. Wang YX, Song L, Xing AJ, Gao M, Zhao HY, Li CH, et al. Predictive value of cumulative blood pressure for all-cause mortality and cardiovascular events. Sci Rep. 2017;7:41969.

30. Sotoodehnia N, Li G, Johnson CO, Lemaitre RN, Rice KM, Rea $\mathrm{TD}$, et al. Genetic variation in angiotensin-converting enzymerelated pathways associated with sudden cardiac arrest risk. Heart Rhythm. 2009;6:1306-14.

31. Wu X, Zhu B, Zou S, Shi J. The association between ACE2 gene polymorphism and the stroke recurrence in Chinese population. $\mathrm{J}$ Stroke Cerebrovasc Dis. 2018;27:2770-80.

32. Yang W, Huang W, Su S, Li B, Zhao W, Chen S, et al. Association study of ACE2 (angiotensin I-converting enzyme 2) gene polymorphisms with coronary heart disease and myocardial infarction in a Chinese Han population. Clin Sci. 2006;111:333-40.

33. Chaoxin J, Daili S, Yanxin H, Ruwei G, Chenlong W, Yaobin T. The influence of angiotensin-converting enzyme 2 gene polymorphisms on type 2 diabetes mellitus and coronary heart disease. Eur Rev Med Pharmacol Sci. 2013;17:2654-9.

34. Wu YH, Li JY, Wang C, Zhang LM, Qiao H. The ACE2 G8790A polymorphism: involvement in type 2 diabetes mellitus combined with cerebral stroke. J Clin Lab Anal. 2017;31. https://doi.org/10. 1002/jcla.22033.

35. Vangjeli C, Dicker P, Tregouet DA, Shields DC, Evans A, Stanton AV, et al. A polymorphism in ACE2 is associated with a lower risk for fatal cardiovascular events in females: the MORGAM project. J Renin Angiotensin Aldosterone Syst. 2011;12:504-9.

36. Palmer BR, Jarvis MD, Pilbrow AP, Ellis KL, Frampton CM, Skelton L, et al. Angiotensin-converting enzyme 2 A1075G polymorphism is associated with survival in an acute coronary syndromes cohort. Am Heart J. 2008;156:752-8.

37. Hu C, Jia W. Diabetes in China: epidemiology and genetic risk factors and their clinical utility in personalized medication. Diabetes. 2018;67:3-11.

38. Jacobson TA, Ito MK, Maki KC, Orringer CE, Bays HE, Jones $\mathrm{PH}$, et al. National Lipid Association recommendations for patient-centered management of dyslipidemia: Part 1 - executive summary. J Clin Lipidol. 2014;8:473-88.

39. Lu Y, Wang P, Zhou T, Lu J, Spatz ES, Nasir K, et al. Comparison of prevalence, awareness, treatment, and control of cardiovascular risk factors in China and the United States. J Am Heart Assoc. 2018;7:e007462.

40. Lieb W, Graf J, Gotz A, Konig IR, Mayer B, Fischer M, et al. Association of angiotensin-converting enzyme 2 (ACE2) gene polymorphisms with parameters of left ventricular hypertrophy in men. Results of the MONICA Augsburg echocardiographic substudy. J Mol Med. 2006;84:88-96.

41. Sardana M, Lessard D, Tsao CW, Parikh NI, Barton BA, Nah G, et al. Association of left atrial function index with atrial fibrillation and cardiovascular disease: The Framingham Offspring Study. J Am Heart Assoc. 2018;7:e008435.

42. Kumar A, Rani B, Sharma R, Kaur G, Prasad R, Bahl A, et al. ACE2, CALM3 and TNNI3K polymorphisms as potential disease modifiers in hypertrophic and dilated cardiomyopathies. Mol Cell Biochem. 2018;438:167-74.

43. Feng W, Sun L, Qu XF. Association of AGTR1 and ACE2 gene polymorphisms with structural atrial fibrillation in a Chinese Han population. Pharmazie. 2017;72:17-21.

44. Dzau V, Braunwald E. Resolved and unresolved issues in the prevention and treatment of coronary artery disease: a workshop consensus statement. Am Heart J. 1991;121:1244-63.

45. Jia G, Aroor AR, Hill MA, Sowers JR. Role of renin-angiotensinaldosterone system activation in promoting cardiovascular fibrosis and stiffness. Hypertension. 2018;72:537-48.

46. Alghamri MS, Weir NM, Anstadt MP, Elased KM, Gurley SB, Morris M. Enhanced angiotensin II-induced cardiac and aortic remodeling in ACE2 knockout mice. J Cardiovasc Pharmacol Ther. 2013;18:138-51.

47. Thomas MC, Pickering RJ, Tsorotes D, Koitka A, Sheehy K, Bernardi S, et al. Genetic Ace2 deficiency accentuates vascular inflammation and atherosclerosis in the ApoE knockout mouse. Circ Res. 2010;107:888-97.

48. Chen YY, Zhang P, Zhou XM, Liu D, Zhong JC, Zhang CJ, et al. Relationship between genetic variants of ACE2 gene and circulating levels of ACE2 and its metabolites. J Clin Pharm Ther. 2018;43:189-95. 